\title{
RAÚL SERRANO: DIALÉCTICA Y CREACIÓN TEATRAL
}

\section{Dialéctica del trabajo creador del actor}

Raúl Serrano ${ }^{1}$ estudioso de teatro, tiene una formación completamente diferente con respecto a la de los hombres de teatro argentino; es, con toda seguridad, la persona que más profunda y científicamente se ha dedicado al estudio de K. Stanislavskij en el ámbito del teatro de este país. La experiencia teatral adquirida en Europa influenciará profundamente sobre este autor en sus investigaciones, de tal modo que al regresar a su país de origen será profundamente crítico con respecto a la realidad stanislavskijana que vivía el teatro argentino en aquellos momentos. Recuerda Serrano que eran muchos los talleres donde cada maestro impartía lecciones siguiendo su propia interpretación del sistema. El panorama general se presentaba privo de coherencia y sistematicidad. El psicoanálisis, en aquellos años, reinaba en Argentina y la barrera que dividía la terapia y el teatro se presentaba por demás débil. Para Serrano el uso del instrumento del actor era utilizado para liberar las neurosis personales. Justamente esta falta de sistematicidad y esta interpretación psicoanalítica del trabajo del actor se encuentran en fuerte contraste con la formación prevalentemente sociológica de este estudioso argentino y por ende opuesta a una interpretación psicoanalítica.

En estas circunstancias Serrano abre una nueva corriente crítica teatral desarrollando sus teorías y sus interpretaciones sobre el teatro y sobre el trabajo del actor. En contraste con las corrientes psicoanalíticas en boga, no colocará, al centro de sus investigaciones, el inconsciente como motor de la conducta humana sino, por el contrario, el trabajo entendido como "praxis creadora, liberatoria, portadora de conocimiento y de una ineludible fuente de reflexión creadora". ${ }^{2}$ Será tomado en consideración el sujeto que surge del trabajo, que es activo y transformador, cuya esencia es entendida como resultante de sus relaciones sociales.

La inquietud que acompaña a Serrano se refiere a una metodología de trabajo teatral, basada en criterios objetivos que puedan proponer al actor una técnica de trabajo. Partiendo de un análisis crítico del Sistema de Stanislavskij, y sobre todo de las investigaciones

1 R. Serrano nace en San Miguel de Tucumán en 1934. En 1961 termina sus estudios de teatro en Rumania, en el Institutul de Arta Teatrala si Cinematografica Ion Luca Caragiale de Bucarest. Hace cursos de perfeccionamiento con J. B. Priestley, Jean Vilar y L. Strasberg. Publica el libro Dialéctica del trabajo creador del actorensayo crítico sobre el método de las acciones fisicas de Stanislavskij y los siguientes ensayos: Arte, ideología y sociedad (1974), Estética y conocimiento (1975), El valor estético (1975), La creación artística como forma de militancia (1984), La estructura dramática (1985). Desanolla la actividad didáctica y de director. En 1990 recibe el Premio Nacional otorgado por la Universidad de La Plata por su actividad artística y de investigación.

2 R. Serrano, Dialéctica del trabajo creador del actor-ensayo critico sobre el método de las acciones fisicas de Stanislavskij, Buenos Aires, Adans S.A., 1981, p. 16. 
llevadas a cabo por el maestro ruso en el último período de su vida — se trata por lo tanto de aquella fase en la que Stanislavskij propone una metodología de trabajo actoral basada en las acciones físicas- Serrano trata de sistematizar y reordenar algunos conceptos fundamentales con el fin de impostar una nueva visión metodológica referida al trabajo del actor. Por lo tanto, intenta hacer del trabajo del actor una ciencia posible de objetivar teóricamente. Dice Serrano:

"Tras las huellas del maestro ruso, opinamos que puede someterse la técnica del actor a la condición de objeto de una ciencia, que podrá ser fundada en el análisis objetivo de las mismas técnicas probadas hasta el momento. La clave de la ciencia del teatro se halla fuera de él, en las numerosas ciencias conexas."3

Esta última consideración no debe ser concebida en el sentido de transposición en ámbito teatral de las metodologías usadas en otras artes. Por el contrario, es necesario que sea efectuado un trabajo interdisciplinario donde los métodos y los instrumentos conceptuales de las ciencias más desarrolladas contribuyan a la fundación de una nueva ciencia teatral.

En el libro Dialéctica del trabajo creador del actor ${ }^{4}$ Serrano expone largamente sus teorías. La obra de K. Stanislavskij representa, para Serrano, el comienzo de la teorización y sistematización de las técnicas teatrales, donde los diferentes procedimientos del trabajo actoral son colocados en su justo sitio, logrando de este modo una demitificación y desacralización del arte del actor. Sin embargo algunos aspectos del trabajo del maestro ruso deben ser analizados críticamente. Si, por otra parte, Stanislavskij expone de manera orgánica los elementos constituyentes del trabajo del actor, por otra deja de lado un análisis profundo de las conexiones que deben existir entre estos elementos. Las tesis de Stanislavskij ofrecen siempre la libertad de llegar a conclusiones subjetivas, justamente porque falta la descripción de un proceso creativo. Nos encontramos por lo tanto frente a una serie de actividades inconexas en donde falta la explicación de su verdadera relación. $\mathrm{El}$ actor debe encontrar sus "si", sus "circunstancias dadas", la atención justa, la verdad en la escena, la memoria emotiva, etc., todo al mismo tiempo, lo que, para Serrano, corresponde a no decir nada. Se presenta por lo tanto como absolutamente necesaria la explicación de un proceso de interrelación entre estos elementos, tratando de establecer un orden temporal, de necesidad y de causalidad entre ellos.

En los últimos años de su vida Stanislavskij mismo había sentido la exigencia de encontrar una coherencia sistemática en el proceso creador del actor. En 1938, dice Serrano, Stanislavskij subraya "la incapacidad del actor para ordenar o forzar sus emociones". 5

"Muchas de las más importantes facetas de nuestra compleja naturaleza no están sujetas a control consciente... nosotros podemos controlar sólo par-

3 Ibidem, p. 11.

4 Ibidem.

5 Ibidem, p. 52. 
cialmente nuestro complejo aparato creativo para la vivencia y la encarnación sobre el escenario."6

Serrano considera que en el capítulo dedicado a El revisor de Gogol, Stanislavskij expone de manera coherente sus nuevas posiciones criticando a su vez algunas formulaciones precedentes. Antes que nada rechaza categóricamente la manera tradicional de encarar la obra a través del análisis de mesa; dice el mismo Stanislavskij:

“¿Para qué estar sentados durante meses y meses frente a la mesa, tratando de expresar desde el interior de uno mismo el sentimiento adormecido? ¿Para qué obligarlo a vivir al margen de la acción?"7

Este “¿Para qué obligarlo a vivir al margen de la acción?” implica para Serrano una nueva propuesta - si bien todavía implícita - de análisis para el actor, que se plantea ahora en términos prácticos: el actor se extrae de la teoría y se vincula a la acción. El instrumento de análisis es entonces la personalidad psico-física del actor y la línea ininterrumpida de las acciones físicas se transforma ahora en el objeto de investigación, es decir la conducta material y objetiva del personaje. Será suficiente que el actor conozca en términos muy generales la situación de una escena para seguir desarrollando su trabajo. Se abandona así la propuesta de trabajo que tenía sus orígenes en el texto dramático. No es el texto el que tiene que ser desmenuzado sino la conducta del personaje. Para Serrano, en el momento de la lectura, el objeto de conocimiento (la estructura dramática compleja) todavía no existe. El texto ofrece los puntos de partida esenciales sobre los cuales se creará la obra dramática, pero su desarrollo en la realidad concreta del escenario depende de numerosos factores que intervienen en el proceso de creación. El texto se presenta, por ende, sólo como uno de los tantos factores que componen la compleja realidad del teatro.

Empezar el trabajo de la puesta en escena de un espectáculo partiendo de la acción dada y no del análisis de mesa "respeta plenamente los requerimientos de un proceso gnoseológico objetivo y material" 8 , basado sobre la observación objetiva y científica de aquello que sucede sobre la escena. El método de las acciones fisicas es para Serrano un método de búsqueda, un instrumento de análisis y no un método de puesta en escena, en cuanto no se encuentran en él todos los elementos propios de la creación artística; se trata por ende, de un método particular de conocimientos. El método no produce sobre la escena un objeto estético, sino más bien "un objeto criterio" - según su definición- un objeto existente fuera de la conciencia que nos permite un análisis más profundo que tendrá como fin la elaboración propiamente estética. Varios hechos que tienen lugar sobre la escena no pueden ser comprendidos sino haciéndolos. Es claro entonces cuánto es difícil trazar una frontera divisoria real entre el objeto estético y gnoseológico, producto de la aplicación del método. De esta manera resume Serrano en qué consiste la esencia de su búsqueda:

\footnotetext{
6 Cit. en R. Serrano, ibidem, p. 52.

7 Cit. en R. Serrano, ibidem, p. 66.

8 Ibidem, p. 67.
} 
"Nuestra investigación se centra sobre la exterioridad, sobre la conducta física del actor, sobre sus comportamientos materiales y objetivos. Pero eso sí, los concebimos como generadores de interioridad psicológica y en estrechos vínculos dialécticos con ella. El personaje se nos aparece como la totalidad de sus relaciones dramáticas (perdónesenos el parafraseo). Y por lo tanto es en ellas en donde tenemos que buscar la génesis de la psicología individual propia del personaje. El actor, al accionar podrá transformar su entorno dramático, su circunstancia escénica. No sólo hace progresar el conflicto modificando a su partner, sino que y fundamentalmente, se transforma él mismo. Es más: se crea a sí mismo como personaje y así el trabajo del actor aparece como un modo particular, con lo que esto implica de identidad y diferencia, del trabajo humano."9

\section{Técnica y poética}

Estos dos conceptos han sido introducidos en el ámbito de la investigación teatral por Raúl Serrano. A partir de la publicación del libro Dialéctica del trabajo creador del actor hasta nuestos días las teorías de Serrano han tenido larga difusión. Numerosos son los colaboradores ${ }^{10}$ ocupados en la investigación y difusión del método del trabajo actoral propuesto por Serrano. Es algo ya confirmado, actualmente en Argentina, que existen dos enfoques metodológicos en la enseñanza del arte del actor (el que concierne a la primera parte del trabajo propuesto por Stanislavskij, con los agregados realizados por Strasberg; y el que se refiere al segundo Stanislavskij, o mejor dicho con los cambios efectuados por Serrano y sus colaboradores). Por lo que se refiere a las acciones físicas, es sabido que Stanislavskij no logró terminar todas las investigaciones que hubiera querido. Se trata, en efecto, de unas cincuenta páginas que hablan de esta nueva propuesta de trabajo. Por lo tanto es en el ámbito argentino que nacen y se consolidan algunos criterios fundamentales que no son ya el método de las acciones físicas de Raúl Serrano.

Técnica y poética. Dice Serrano:

"Hay infinidad de poéticas, pero lo que yo sostengo es que hay solamente dos técnicas posibles." 11

¿Qué entiende Serrano por técnica en el ámbito teatral?

"La técnica sería la descripción del instrumento y de la materia y de los procedimientos que se usan para transformar la materia en algo previsto."12

9 Ibidem, p. 18.

10 Rubens Correa, José Boves, Pedro Espinosa, profesores de la Escuela Municipal de Buenos Aires y profesores de la Escuela Nacional de Buenos Aires.

11 Entrevista de A.C.P. a R. Serrano, Buenos Aires, 1991.

12 Ibidem. 
Explica Serrano: así como en las técnicas de las otras artes, también en la técnica del trabajo del actor se debería determinar el uso de los materiales y de los instrumentos necesarios para transportar aquello que en la vida es natural - porque en la vida los estímulos y sus consecuencias son reales- en un espacio en que los estímulos no pueden ser reales. Comenta Serrano: yo no puedo arrancarle los ojos a Edipo para que sufra. Cada arte tiene su técnica, pero la técnica del actor ha oscilado, en su historia, entre la declamación o sea la recitación basada en el texto, considerado esencial, o bien la representación basada en el cuerpo. Para Serrano ha llegado el momento de encontrar sus relaciones, su síntesis. Se ha dicho que existen infinitas poéticas, tantas poéticas cuantos son los artistas sobre la tierra. Pero no es posible decir lo mismo para la técnica porque ésta está sostenida por leyes naturales. Explica Serrano:

"Si te digo: tienes que volverte invisible; no vas a poder. Si te digo: ódiame, ahora en este momento; tampoco vas a poder. Estos son los límites de la materia."13

Para Serrano existen sólo dos técnicas, dos modos de utilizar el instrumento actor instrumento compuesto por el cuerpo y por la propia psique - ambas introducidas por Stanislavskij: son el primero y el segundo método del maestro ruso. En el primer caso, para crear estímulos reales que en la escena no existen, Stanislavskij propone sustituir los estímulos no con conceptos sino con imágenes que no son puramente visuales, sino también auditivas, tactiles, olfativas, etc., que actúen sobre nosotros provocando conductas orgánicas. Se trata de una técnica introspectiva en la cual en el trabajo de las vivencias se valorizan más las imágenes que la realidad. Strasberg exaspera, según Serrano, este tipo de enfoque a través de ejercicios como el del "momento privado". La técnica introspectiva obstaculiza en parte el contacto de interacción con el otro y da más valor a lo que no existe que a lo que existe, y es por esto que según Serrano, generaciones de actores han tratado de vincular el punto de partida introspectivo con la improvisación "aquí y ahora", sin lograrlo, porque este método no da respuesta a la interacción en la escena. El segundo método, en cambio, parte de la improvisación la cual puede motivar al actor tanto cuanto una imagen. Dice Serrano:

"Cuando le digo al alumno: hagamos de cuenta que soy un ladrón, al minuto está metido en la situación, comprometidísimo."14

Esto sucede porque, si al cuerpo se le arroja en una situación conflictiva, responde con su propia lógica, porque el cuerpo es el sitio del conflicto, el lugar de la emoción.

\section{Estructura dramática}

El concepto de estructura dramática representa el núcleo alrededor del cual existe la posibilidad misma de realizar un análisis del trabajo creativo del actor. Sin este concepto no existe análisis posible a menos que no se confundan continuamente los diferentes nive-

\footnotetext{
13 Ibidem.

14 Ibidem.
} 
les, sociológicos, ideológicos, históricos etc. Se ha visto ya de qué modo Serrano considera al sujeto como resultante de sus relaciones sociales. La conducta humana, en general, implica una interacción que vincula al sujeto con su contexto. El teatro es para Serrano un caso particular de conducta humana: el sujeto —s decir el actor hacia la creación del personaje - y el entorno - la escena - están caracterizados por el hecho de no ser los mismos entre el comienzo del trabajo y su forma final. En el proceso de creación de la obra teatral los diferentes elementos que producen la estructura, se interaccionan mutuamente. La estructura dramática es, por lo tanto, aquel objeto complejo estructurado en la que el actor realiza una función primordial. Escribe Serrano:

"No podemos eludir la siguiente cuestión: todo ensayo parte de las condiciones objetivas de existencia de tal o cual actor y pretende justamente constituirse en el proceso por el cual él mismo comienza a "ser" (recordemos el problema de la vivencia) el personaje. Por otra parte, el entorno está compuesto por ciertas partes reales, de uso objetivo (el suelo, las distancias, las sillas etc.) y otras que simplemente existen como propuestas convencionales pero que debieran influir en los comportamientos del actor "como si" fueran reales en su ascenso hacia el personaje. En estas condiciones, la aparición de los productos buscados (el personaje y la circunstancia teatral imaginaria) condicionan recíprocamente su aparición. Ni el entorno imaginario cobra visos de realidad si la conducta no tiene en cuenta sus implicancias reales y supuestas, ni la conducta resulta creíble si no se adecua a esos condicionamientos... En la práctica material (y por lo tanto en todo análisis dialéctico de la misma) esos elementos componen una estructura en la que el entorno aparece "producido" por el trabajo del actor, y el personaje mismo resulta de la acción del actor que tiene en cuenta los condicionamientos propuestos y los reales." 15

No existe, por lo tanto, estructura dramática sin proceso, ni proceso sin estructura dramática. Epistémicamente se plantea como necesaria la creación de un objeto a partir del yo del actor, que sin duda presenta muchas diferencias con el personaje que está tratando construir, pero que a su vez tiene con éste una cierta identidad de base. Tal identidad existe de hecho en la dimensión biológica-corporal, mientras que la diferencia existe en el plano de lo cultural.

"Biológicamente una actriz no presenta grandes diferencias con la reina Elizabeth, pero sí culturalmente. Y si nos ponemos del lado de la lógica corporal, las diferencias culturales pueden ser por el momento dejadas del lado."16

El punto de partida está siempre ínsito en la lógica del cuerpo, en lograr poner en acto las pulsiones físicas. Crear el objeto a partir de sí mismo permite al actor pensar en el proceso: es decir, una vez que existe el objeto, que el actor está en su lógica corporal (no

\footnotetext{
15 R. Serrano, Dialéctica del trabajo creador del actor, Buenos Aires, Adans, 1981, p. 95.

16 Entrevista de A.C.P. a R. Serrano, Buenos Aires, 1992.
} 
diferente a la del personaje), entonces sí se puede pensar en el proceso. Y, por lo tanto, el proceso es para Serrano un proceso extrovertido: del yo al personaje. Con respecto a la puesta en acto de las pulsiones físicas, la activación de lo cultural se presenta como algo mucho más fácil.

A aquellos que afirman la continuidad entre el primero y el segundo Stanislavskij, sosteniendo que con ambos métodos —introspección y acciones físicas-, se llega al mismo fin, y que por lo tanto, en tal sentido son lo mismo, Serrano responde subrayando la importancia del proceso como noción clave en el trabajo creativo del actor. La diversidad de los itinerarios hace completamente diferentes, también, los objetivos que aparentemente pueden ser similares: una cosa es partir de la acción física y llegar a la vivencia, otra es partir del trabajo introspectivo. Más bien, para Serrano la búsqueda del sentimiento vivido como punto de partida representa el más grave error científico que se pueda haber cometido, y es, fundamentalmente en esto que se opone a Strasberg.

"La estructura que se genera en la intorspección hace que el actor deje de lado el "aquí y ahora", la dialéctica de los cuerpos, la interacción, lo que está pasando a su alrededor, y lo lleva a valorizar el pasado."17

Los elementos constituyentes de la estructura dramática, son, dice Serrano, como las siete notas en música. No sólo se condicionan mutuamente sino que se constituyen como tales debido a su recíproca dependencia. Son:

1) Los conflictos.

2) El entorno, que no se debe confundir con el lugar de la acción.

3) Los sujetos activos.

4) Las acciones físicas o trabajo específico propio del actor.

5) El texto.

El conflicto en su acción técnica es el encuentro entre dos o más conductas voluntarias dentro o fuera del sujeto en cuestión. El conflicto es siempre el oponerse de dos fuerzas antagónicas, de dos modos diferentes de proceder, pero que al mismo tiempo es la unidad, por lo que una fuerza encuentra su razón de ser en la otra y viceversa. Lo que se propone Serrano es resolver el problema técnico del actor cuando se encuentra frente a un conflicto. Explica Serrano que el actor, generalmente, frente a una acción dramática, tiende a describir el conflicto y a analizarlo desde fuera, adoptando casi un punto de vista externo. El actor puede entender los tormentos de Edipo, hablar de ellos, pero permanece irresoluble de qué modo el actor procederá para lograr revivir los sentimientos de su personaje. El plan puramente descriptivo se abandona a favor de una interiorización del conflicto. Se trata de lograr traducir la comprensión intelectual en una praxis actoral. El primer paso que el actor debe cumplir es el de visualizar cuáles son los dos o más elementos en contraste que aparecen como tendencias opuestas en su accionar, como propuestas contradictorias para su trabajo específico, de modo que se puedan asumir como tales. El conflicto se deberá presentar siempre como un objetivo a lograr y al cual se opone otro. Los objetivos en contraste pueden pertenecer a diferentes personajes así como subsistir

17 Ibidem. 
dentro de un único personaje. El conflicto, por lo tanto, se asume "fisicamente", se le desliza desde la razón abstracta del actor hacia la materia. Este proceder hace posible que el actor no sólo piense y trate de sentir, sino que efectivamente accione, y que a través de la acción "deje de ser él mismo y comience a ser el personaje que se construye a partir de la propia personalidad". Es el comienzo de aquel proceso de identificación con el personaje que excluye ya al actor toda posibilidad de asumir aquel punto de vista externo mencionado.

Serrano identifica en la acción la unidad mínima a la que puede reducirse lo dramático, en el cual confluyen todos los otros elementos de la estructura dramática. La acción crea, por lo tanto, el entorno. A su vez, también el entorno condiciona el accionar - no olvidemos que la estructura dramática es, en efecto, un esquema conceptual orgánico que posee elementos en relaciones recíprocas. Cada situación dramática en cuanto situación concreta tiene un entorno, es decir un espacio físico real en el que se coloca la acción (el escenario en cuanto tal), un espacio convencional (el escenario como sede del imaginario creado para el accionar de los actores) y el conjunto de las condiciones dadas, visibles en la escena en la medida en que son causa de determinadas transformaciones en el accionar de los personajes.

"La acción escénica es todo comportamiento voluntario y consciente, que tiende a un determinado fin y que transforma, aquí y ahora." Es la definición de Serrano, que hace hincapié en la capacidad que tiene la acción de transformar el campo en la que se aplica.

La acción es principalmente el instrumento en que el actor construye el personaje y guía la interacción en la escena. El actor tiene que poder lograr la transformación de su partner transformándose, también, a sí mismo. Él “... debe comenzar su trabajo técnico con las acciones y son éstas las que desencadenan todo el proceso ulterior que engloba a posteriori diversos niveles psicológicos". Son las relaciones materiales con el entorno y con los partners que crean al personaje no sólo en su realidad física sino, también, en la psicológica. Sin embargo, no todo movimiento es acción - en cuanto un movimiento puede, del mismo modo, no implicar transformación-, mientras que toda acción es movimiento. Pero la acción no puede ser reducida a simple movimiento sobre todo porque éste último deja fuera de sí la psiquis del personaje. Serrano subraya el hecho de que la acción escénica para responder a su característica principal de "transformadora", debe necesariamente presentarse como acción psico-física: si la acción fuera únicamente acción física, no sería posible diferenciarla del simple movimiento; si fuera únicamente psíquica, sería imposible para el espectador percibirla.

Para Serrano se hace imposible distinguir lo que se crea, de la cosa creada; el actor es materia, instrumento, es el que crea, indistintamente. En él real e imaginario se funden. De este modo la acción lo transforma en otro, en el personaje construido sobre su propia identidad. El actor, a través de las acciones que no le pertenecen deja de ser él mismo para asumir el personaje e identificarse con él. El actor haciendo lo que hace el personaje, se transforma lentamente en éste. El sujeto de la estructura dramática es, por lo tanto, el sujeto que se va creando a partir del actor, el personaje en su desarrollo. 
Por lo que se refiere a este tema, en estos últimos años, Serrano amplía y modifica algunas de sus concepciones precedentes. El sujeto, considerado inicialmente como orientado hacia la finalidad, se enriquece actualmente de consideraciones ulteriores: no es más sólo aquél que quiere algo, sino aquél que de continuo tropieza con conflictos. El sujeto, en el momento de accionar, se encuentra ante un conflicto, por ejemplo, entre una res-

puesta y un estímulo en consonancia a su instinto y a su ser social. En este contexto, la conversación dramática se convierte en una salida conflictiva, la transfiguración de la represión actuada desde la cultura sobre el cuerpo.

Del mismo modo, Serrano redefine el concepto de acción como comportamiento voluntario que afronta el conflicto y trata de resolverlo en la búsqueda de un compromiso con dicho conflicto. No hay más espacio para ningún tipo de racionalización, el sujeto no se pregunta qué quiere y por qué, sino que sufre la lógica conflictual del cuerpo como motor en el "aquí y ahora". La acción como lucha a lo que se nos impone. Esta reelaboración de las temáticas le quita al libro de Serrano un poco de aquel sabor racionalista del cual está impregnado.

Lo que sucede con el entorno, que crea la acción y que a su vez es creado por ella, se encuentra, en cierto modo, también, en el texto teatral que es, ya sea premisa para el trabajo del actor (es el indicio del cual se parte) ya consecuencia del mismo (o sea el resultado verbal necesario de las existencias de las relaciones materiales en la escena). Lo que fundamentalmente exige el trabajo técnico es la investigación de los elementos que no se traslucen del plano verbal, es decir de todos aquellos factores extralingüísticos en que se desarrolla el acto lingüístico. El actor con sus acciones, justamente, construye dichos contextos materiales. Por otra parte, el texto necesariamente condiciona el accionar del actor, y en tal sentido funciona como una condición dada.

La obra de Serrano se coloca en la necesidad de recuperar la unidad del ser humano como-base de toda ética, de colmar la distancia entre palabra y cuerpo.

\section{Povzetek}

\section{RAÚL SERRANO: DIALEKTIKA IN GLEDALIŠKO USTVARJANJE}

Pričujoči članek je del publikacije, ki bo v kratkem izšla v Buenos Airesu in ki govori o "Odmevih metode K. Stanislavskega $v$ argentinskem gledališču”. V tem eseju je posebej predstavljena in analizirana metoda dela $\mathrm{z}$ igralcem, kot jo predlaga argentinski gledališki teoretik Raúl Serrano, med drugim tudi avtor knjige Dialektika igralčeve ustvarjalnosti, ki v svoji teoriji izhaja iz "metode fizičnih zaposlitev" K. Stanislavskega, in na svojstven način razglablja o nujnosti odnosa med dialektiko in kreativnostjo v igralčevem delu.

Ta argentinski pedagog na kritičen način analizira tudi teorijo ameriškega gledališkega pedagoga Leeja Strasberga. 